\title{
WESTFALIA, WORLDFALIA, EASTFALIA. EL IMPACTO DE LAS TRANSFORMACIONES DE LA ESTRUCTURA DE PODER INTERESTATAL EN EL ORDEN INTERNACIONAL
}

\author{
Caterina García Segura*
}

SUMARIO: 1. INTRODUCCIÓN: WESTFALIA, WORLDFALIA, EASTFALIA.-2. LAS TRANSFORMACIONES DE LA ESTRUCTURA DE PODER INTERESTATAL.-2.1. El siglo de Asia.-2.2. ¿Qué estructura de poder interestatal?-3. LAS TRANSFORMACIONES EN EL ORDEN INTERNACIONAL.-3.1. ¿Transformación o declive del orden internacional liberal?-3.2. La evolución cosmopolita del orden liberal.-4. LAS POTENCIAS ASIÁTICAS EMERGENTES FRENTE AL ORDEN INTERNACIONAL: DE RECEPTORAS A CREADORAS DE NORMAS.-4.1. La dinámica de las normas y los roles normativos en el orden internacional.-4.2. El rol de las potencias asiáticas emergentes en los procesos normativos del orden internacional.-5. EL IMPACTO DEL ASCENSO DE CHINA SOBRE INSTITUCIONES Y NORMAS DEL ORDEN INTERNACIONAL.-5.1. China y el multilateralismo.-5.2. China y la Responsabilidad de Proteger.-6. CONCLUSIÓN.

\section{INTRODUCCIÓN: WESTFALIA, WORLDFALIA, EASTFALIA}

Desde finales del siglo pasado el sistema interestatal asiste a cambios importantes en su estructura de poder y en algunas de las normas e instituciones del orden que pauta su funcionamiento. Tras el colapso de la Unión Soviética y el fin de la bipolaridad, el siglo XXI está viendo cómo se cumplen y se superan todas las previsiones que, desde los años ochenta, anunciaban que este sería el "siglo de Asia» ${ }^{1}$. Que los países emergentes de Asia han aumentado sus capacidades materiales está fuera de toda duda. Hasta qué punto este traslado del centro de gravedad del sistema se traducirá en cambios en el orden internacional o en un cambio de orden

* Catedrática de Relaciones Internacionales en la Universitat Pompeu Fabra (caterina.garcia@upf. $e d u$ ). Todas las páginas web de referencia han sido consultadas por última vez el 2 de junio de 2017.

1 En sentido amplio, la idea de Asia que inspira el concepto de «siglo asiático» incluye los diferentes subconjuntos regionales si bien el centro y el motor se identifica con Asia oriental. En cuanto a países, en base a las previsiones de crecimiento económico y demográfico, China e India, seguidos por Indonesia, son los mayores protagonistas del impulso emergente asiático. 
internacional es aún una incógnita, y será la cuestión que nos ocupará en las próximas páginas. Este trabajo pretende, a partir de la constatación del auge económico de las potencias asiáticas, aprehender la relación mutuamente constituyente entre poder y orden en la sociedad internacional contemporánea. En concreto estudiará la relación entre los cambios en la estructura de poder interestatal y la transformación de algunas de las normas e instituciones del orden internacional contemporáneo. Lo hará en línea con los trabajos que, de la mano del constructivismo, han propuesto un «giro ideacional», de «retorno a las normas», recuperando algunas de las preocupaciones tradicionales de las Relaciones Internacionales y dando espacio a las cuestiones ideacionales que habían permanecido marginadas por una sobrevaloración de las materiales ${ }^{2}$. La pregunta a la que pretende responder es si la nueva posición de las potencias asiáticas emergentes en la jerarquía de poder interestatal está generando cambios normativos en el orden liberal liderado por Estados Unidos ${ }^{3}$ y, en caso afirmativo, en qué dirección avanzan.

En el marco de las reflexiones sobre la rivalidad entre Estados Unidos y China y, de manera más amplia, entre Occidente y las potencias asiáticas emergentes, este trabajo analiza la interrelación constitutiva entre poder y orden: cómo se traduce el crecimiento económico de las potencias asiáticas emergentes en poder político y normativo, y cómo impacta sobre el orden internacional contemporáneo. Frente a las voces alarmistas que acusan a las potencias asiáticas emergentes de querer subvertir el orden internacional contemporáneo y que vaticinan que el orden post-occidental será un orden asiático, la hipótesis que defiende es que esta afirmación dista de ajustarse a la realidad. Por una parte, las potencias asiáticas han demostrado ser defensoras acérrimas del principio organizativo básico de las estructuras constitucionales del orden internacional ${ }^{4}$, la soberanía estatal en clave westfaliana, mientras que las potencias tradicionales, al menos a nivel discursivo, han ido admitiendo su evolución en pro de principios de inspiración cosmopolita ${ }^{5}$. Por otra, si bien están ejerciendo una acción transformadora o moldeadora sobre algunas instituciones, como el multilateralismo, generando su propia versión, no proponen sustituir las existentes.

2 Finnemore, M. y SikKInK, K., «International Norm Dynamics and Political Change», International Organization, vol. 52, otoño 1998, núm. 4, pp. 887-917, p. 888.

3 Ikenberry, G. J., Liberal order and Imperial Ambition, Cambridge, Polity Press, 2004.

4 Reus-Smit, C., "The Constitutional Structure of International Society and the Nature of Fundamental Institutions», International Organization, vol. 51, 1997, núm. 4, pp. 555-589.

5 Algunos de los últimos acontecimientos políticos internacionales (populismos, nacionalismos excluyentes, Brexit, Trumpism) ponen de manifiesto la debilidad del giro cosmopolita de la sociedad internacional. Como hemos defendido anteriormente, el cosmopolitismo contemporáneo es un cosmopolitismo blando o suave que se caracteriza «por un décalage entre su defensa retórica y su plasmación en normas concretas y por la concepción del corpus cosmopolita más como ideal o fuente de inspiración que como guía programática». García SEgura, C., "Introducción», en García Segura, C. (dir.), La tensión cosmopolita. Avances y límites en la institucionalización del cosmopolitismo, Madrid, Tecnos, 2016, pp. 13-19, p. 16. Sobre las contradicciones del cosmopolitismo, véase HeLD, D., Cosmopolitismo. Ideales y realidades, Madrid, Alianza Editorial, 2010. 
En cuanto al orden internacional este trabajo defenderá que es más permanente que la hegemonía que lo creó $^{6}$. A pesar de las transformaciones en curso, el orden de Westfalia —en su versión evolucionada, el orden liberal- sigue vigente, Worldfalia es un proyecto y Eastfalia es un desafío más retórico que real. Entendemos por Westfalia el orden que ha desarrollado los principios, normas e instituciones que han consagrado el sistema de Estados soberanos. Sin alterar el principio organizativo, en terminología de Christian Reus-Smit, o la fuente del orden, en terminología de John Ikenberry, el orden westfaliano ha ido evolucionando hacia el orden liberal, capitaneado en el siglo XIX por Gran Bretaña y en el siglo XX por Estados Unidos. Utilizamos Worldfalia para referirnos al «nuevo modelo de orden internacional, que aún no existe como tal, pero que se deja entrever en la evolución de algunos debates normativos de la sociedad internacional» ${ }^{7}$. Coincide parcialmente con la última fase en la evolución del proyecto liberal identificada por John Ikenberry, caracterizada por la adopción de una agenda de defensa de los derechos humanos, representada por la norma emergente de la Responsabilidad de Proteger $(\mathrm{RdP})^{8}$. La deriva cosmopolita de Worldfalia está liderada sobre todo por algunas organizaciones internacionales y por actores de la sociedad civil global, mientras que los Estados responden a las presiones de los actores líderes articulando una narrativa cosmopolita. Sin embargo, en la práctica permanecen anclados en Westfalia y, mayoritariamente, se resisten a formalizar sus compromisos en normas e instituciones de carácter vinculante. Finalmente, Eastfalia es un término que se refiere al hipotético orden internacional que se erigiría sobre la preponderancia de Asia como centro de poder mundial y pivotaría alrededor de principios y prácticas de origen asiático. Por extensión, se utiliza tanto para referirse al nuevo protagonismo asiático en las relaciones internacionales como a la perspectiva asiática ante el Derecho internacional y las instituciones internacionales ${ }^{9}$.

Para aprehender la naturaleza de todos estos procesos el trabajo analizará, en primer lugar, las transformaciones materiales de la estructura del poder interestatal. En segundo lugar, considerará la transformación del orden internacional liberal. En tercer lugar, estudiará el posicionamiento de las potencias asiáticas emergentes respecto del orden internacional y su transformación pasando de ser receptoras a creadoras de normas. En cuarto lugar, analizará el impacto del ascenso de Asia sobre la institución del multilateralismo y la norma de la RdP.

${ }^{6}$ Keohane, R. O., After Hegemony. Cooperation and Discord in World Political Economy, Princeton, Princeton University Press, 1984; Ikenberry, G. J. (ed.), Power, Order, and Change in World Politics, Cambridge, Cambridge University Press, 2014.

7 García Segura, C., op. cit., nota 5, pp. 15-16.

8 IKEnBerry, G. J., op. cit., nota 6, p. 95.

9 Término acuñado por: KIM, S. W., Eastphalia Rising: An Enquiry into the Emergence of Asian Perspective on International Law and Global Governance. Tesis doctoral, Indiana University, 2008. Cit. por GINSBURG, T., «Eastphalia and Asian Regionalism», University of California Davis Law Review, vol. 44, 2011, núm. 3, pp. 859-877, p. 859. KIM, S. W., Fidler, D. P. y Ganguly, S., «Eastphalia Rising? Asian Influence and the Fate of Human Security?», World Policy Journal, vol. 26, 2009, núm. 2, pp. 56-64. 


\section{LAS TRANSFORMACIONES DE LA ESTRUCTURA DE PODER INTERESTATAL}

\subsection{El siglo de Asia}

«El crecimiento de Asia está cambiando el mundo. Es el hecho distintivo del siglo XXI, el siglo de Asia ${ }^{10}$. Esta cita refleja un hecho empíricamente observable e indiscutido: el centro del poder económico mundial se está desplazando hacia Asia ${ }^{11}$.

Las proyecciones económicas actuales esbozan un futuro en el que China e India (Chindia) ${ }^{12}$ serán las mayores economías. En 2050 China será la mayor economía mundial, India superará a Estados Unidos, que pasará al tercer puesto, e Indonesia ocupará el cuarto. El siglo asiático será liderado por siete países —China, India, Indonesia, Japón, Corea del Sur, Malasia y Tailandia-que en 2050 representarán el 50 por 100 del PNB mundial (un 20 por 100 del cual corresponderá a China) y el 90 por 100 del PNB de Asia ${ }^{13}$. El crecimiento asiático se acompañará de una caída de las posiciones de Europa y Estados Unidos (15 y 12 por 100 del PIB mundial respectivamente) ${ }^{14}$. Los analistas estadounidenses asumen el declive de Estados Unidos aunque apuntan que el país continuará siendo el más poderoso porque en ningún escenario plausible otra potencia podrá desplegar la misma panoplia de poder $^{15}$.

Mayores dudas plantea el modelo de la nueva configuración del poder mundial a la que dará lugar el presente desplazamiento del poder EuroAtlántico hacia Asia y los efectos que tendrá sobre el conjunto. Algunas prospectivas anuncian una mayor incertidumbre, peligros de fragmentación y un vacío de gobernanza. Otras condicionan el éxito asiático a que China e India abandonen la sospecha mutua y la competición estratégica y se conviertan en colaboradoras. De no lograrlo, Estados Unidos seguiría siendo indispensable para el equilibrio de poder regional, aceptado por India, Japón y otros países del sudeste asiático como contrapeso imprescindible de China ${ }^{16}$.

\footnotetext{
10 Australian Government, Australia in the Asian Century. White Paper, Camberra, Department of the Prime Minister and Cabinet, 2012.

11 Borthwick, M., Pacific Century: The Emergence of Modern Pacific Asia, Boulder, Westview Press, 1998; Hsiung, J. C., Twenty-First Century World Order and the Asia Pacific, Nueva York, Palgrave, 2001; Soon, L. T. y Suryadinata, L. (eds.), Moving into the Pacific Century: the Changing Regional Order in the Asia-Pacific, Singapur, Heinemann Asia, 1988.

12 Vasconcelos, A. (ed.), Citizens in an Interconnected and Polycentric World. Global Trends 2030, París, EU ISS, 2011, pp. 116-117.

13 Price Waterhouse CoOpers, The Long View. How will the global economic order change by 2050?, Londres, PWC, 2017, pp. 39 y ss.

14 Ibid., p. 16.

15 National Intelligence Council, Global Trends 2030: Alternative Worlds, Washington DC, NIC, 2012.

16 VAsconcelos, A., op. cit., nota 12, p. 107.
} 
Otras consideraciones conducen a análisis menos pesimistas o radicales. Por una parte, la difuminación de la hegemonía de Estados Unidos no implica que vaya a sustituirle, en las mismas condiciones, otra potencia hegemónica. La época en que una única superpotencia ejercía un dominio global, como en su momento hicieran Gran Bretaña y Estados Unidos, ha acabado ${ }^{17}$. El contexto actual es muy distinto a aquel en que se configuró la hegemonía estadounidense. No ha habido una gran guerra ni China tiene el ascendente sobre las grandes potencias del sistema que tenía Estados Unidos en su momento. Por otra parte, en el siglo XXI el poder económico no se convierte automáticamente en hegemonía global. La hegemonía resulta de combinar capacidades materiales, ideas e instituciones ${ }^{18}$. La influencia política no aumenta en tándem con la riqueza y el tamaño. El estatus internacional es una suma de capacidades materiales, poder blando y capacidad para forjar el consenso interno que permita una política exterior coherente ${ }^{19}$. De momento Asia aumenta sus capacidades materiales, pero Occidente retiene el control sobre ideas e instituciones. Sin embargo, el panorama podría cambiar porque las potencias asiáticas van adquiriendo conciencia de que, en un contexto de difusión del poder ${ }^{20}$, el poder blando adquiere mayor relevancia. Aunque son relativamente neófitas en la construcción del poder blando, están invirtiendo intensivamente en diplomacia pública ${ }^{21}$. No obstante, como recoge el ranking global The Soft Power 30, a pesar de sus esfuerzos políticos e inversiones económicas, China e India han avanzado poco en la conquista del poder blando ${ }^{22}$. En 2016 China ocupaba la posición 28, solo dos por delante respecto a 2015 e India ocupaba la 34, también dos posiciones por delante respecto a la anterior. El poder blando también se caracteriza por su durabilidad, una vez conseguido. Así, mientras las potencias asiáticas lo intentan, Estados Unidos, a pesar de la seria erosión del poder blando sufrida a inicios de la década anterior $^{23}$, sigue ocupando el primer lugar gracias a la fortaleza de su educación superior, la producción cultural y la innovación tecnológica, capaces de compensar los desatinos de su política exterior ${ }^{24}$. El atractivo del «síndrome HHMM» (Harvard and Hollywood, McDonald's and Microsoft) ${ }^{25}$ sigue imba-

17 Acharya, A., The End of American World Order, Cambridge, Polity Press, 2014, p. 4.

18 Cox, R. W., "Social Forces, States and World Orders: Beyond International Relations Theory», Millennium, vol. 10, 1981, núm. 2, pp. 126-155.

19 ACHARYA, A., op. cit., nota 17, p. 107.

20 NyE, J., «The Changing Nature of World Power», Political Science Quarterly, vol. 105, 1990, núm. 2, pp. 177-192.

21 Véase: Mellissen, J. y Sohn, Y., Understanding Public Diplomacy in East Asia, Nueva York, Palgrave/Macmillan, 2015.

22 McGlory, J., The Soft Power 30. A Global Ranking of Soft Power, Londres, Portland, 2007, disponible en: https://softpower30.portland-communications.com/wp-content/themes/softpower/pdfs/the_soft_ power_30.pdf.

${ }^{23}$ Haure, J. J., «Foreword. Restoring America's International leadership», en ARMitage, R. L. y NyE, J., CSIS Commission on Smart Power. A smarter, more secure America, Washington, CSIS, 2007, pp. 3-4, p. 3 .

24 McGloRY, J., op. cit., nota 22, pp. 38-39.

25 Joffe, J., "Who is Afraid of Mister Big?», The National Interest, verano 2001. Disponible en: http://nationalinterest.org/article/whos-afraid-of-mr-big-1201. 
tible. No obstante, como el poder es complejo y difuso, el poder global estadounidense es contestado en otros frentes ${ }^{26} \mathrm{y}$ la estructura del poder mundial sigue cambiando.

\section{2. ¿Qué estructura del poder interestatal?}

La complejidad de las formas que adopta el poder actualmente y su difusión explica que no sea posible identificar la estructura actual con ninguno de los modelos ideales clásicos. Todas las fórmulas híbridas que han sido propuestas para describir la nueva configuración del poder interestatal, aun teniendo mayor o menor valor explicativo, son problemáticas porque adolecen de ciertas carencias: se centran en los reequilibrios del poder interestatal, obviando el poder disputado por actores no estatales; dan una imagen fija del poder, ignorando la alternancia de los ámbitos relevantes y de los recursos susceptibles de convertirse en claves del poder mundial en un mundo global; y se centran en la distribución del poder sin abordar cuestiones nucleares como la naturaleza, las fuentes y los efectos del poder ${ }^{27}$.

Con el fin de integrar en un único concepto las ideas de pluralidad de actores que participan en el reparto de poder (potencias estatales y centros de poder no estatales), asimetría entre ellos (capacidades y habilidades cuantitativa y cualitativamente distintas), fragmentación (versus concentración) y no convertibilidad del poder (el poder en un ámbito no se transforma automáticamente en poder en otro ámbito) hemos propuesto el término de multipolaridad compleja ${ }^{28}$. Supone ampliar el concepto de polos - tradicionalmente circunscrito a los Estados- a actores de diversa naturaleza - tradicionalmente denominados centros de poder-y admitir un equilibrio de poder mucho más complejo que el de la multipolaridad clásica.

En este contexto de multipolaridad compleja el poder interestatal cada vez pivota menos sobre el eje Euro-Atlántico y más sobre el eje Asiático-Pacífico. Muchos analistas interpretan este giro como el inicio del fin de la Pax americana $^{29}$ y el comienzo del "ascenso del resto» que conduciría a una era

26 Amitav Acharya plantea que en un mundo «multiplex» para entender el poder hay que combinar cuatro dimensiones (height, length, depth, time) que nos informan sobre la distribución del poder, la extensión y difusión, la fortaleza y legitimidad y el origen y final en el tiempo. ACHARYA, A., op. cit., nota 17, pp. 10-12.

27 García Segura, C., "China en las relaciones internacionales: hacia la consolidación de la multipolaridad compleja», en Pelegrín, A. y Torroja, H. (eds.), China hoy: claves para entender su posición en el tablero internacional, Barcelona/Madrid, CEI/Marcial Pons, 2014, pp. 19-56; SANAHUJA, J. A., "¿Un mundo unipolar, multipolar o apolar? La naturaleza y la distribución del poder en la sociedad internacional contemporánea», en VVAA, Cursos de Derecho Internacional y Relaciones Internacionales de Vitoria-Gasteiz, 2007, Bilbao, Universidad del País Vasco, 2008, pp. 297-384.

28 García Segura, C., op. cit., pp. 19-56.

29 Boron, T., «Towards a post-Hegemonic Age? The end of Pax Americana», Security Dialogue, vol. 25, 1994, núm. 2, pp. 211-221; KupChan, C. A., "After Pax Americana: Benign Power, Regional Integration, and the Sources of a Stable Multipolarity», International Security, vol. 23, 1998, núm. 2, pp. 40-79; LAYNE, C., "This Time It's Real: The End of Unipolarity and the Pax Americana», International Studies Quarterly, vol. 56, 2012, núm. 1, pp. 203-213. 
post-hegemónica ${ }^{30}$ y a un mundo post-occidental ${ }^{31}$. Pero para ello, las potencias emergentes, una vez conquistados espacios materiales del poder, deben hacerse un espacio en los procesos normativos que generan, mantienen o modifican el orden internacional.

\section{LAS TRANSFORMACIONES EN EL ORDEN INTERNACIONAL}

\section{1. ¿Transformación o declive del orden internacional liberal?}

John Ikenberry plantea que a pesar de la gran transformación en la que está inmerso, "[e]l viejo orden — dirigido por Estados Unidos y sus aliados- tiene todavía una presencia predominante en el sistema global» ${ }^{32}$. Al contrario, Amitav Acharya sostiene que «[e]l orden mundial americano está llegando a su fin, esté o no América en declive» ${ }^{33}$. Este trabajo se posiciona con Ikenberry, en la interpretación de la transformación del orden y no de su sustitución por otro de nueva creación. Las transformaciones en curso no parecen dirigirse, al menos en un futuro cercano, hacia un cambio de orden sino a cambios en el orden. No apuntan a las estructuras constitucionales ${ }^{34}$ o a las normas fundamentales ${ }^{35}$, sino a algunos aspectos de las instituciones fundamentales ${ }^{36} \mathrm{o}$ de los regímenes específicos ${ }^{37}$.

En la actualidad hallamos signos tanto de la preeminencia de la superpotencia como de la erosión de su poder. Del mismo modo, podemos observar la erosión del orden liberal que lidera — de algunas de sus normas e instituciones- y a la vez su vigencia. Y aunque el «siglo de Asia» participa en las erosiones y transformaciones del poder estadounidense y del orden liberal, los cambios no son generados exclusivamente por las potencias asiáticas ni por las emergentes de otras regiones, ni tan solo por el conjunto de todos los actores erosionadores del orden o por los actores subversivos respecto al mismo. También los actores promotores y afianzadores ${ }^{38}$ contribuyen a ellas.

30 ZAKaria, F., The post-American World.Release 2.0, Nueva York, WW. Norton Company, 2011.

31 Jacoues, M., When China Rules the World: The End of the Western World and the Birth of a New Global Order, Westminster, Allen Lane, 2012. Contrario a esta tesis, John Ikenberry sostiene que a pesar del claro ascenso de países no occidentales el orden liberal occidental no está en cuestión. IKENBERRY, G. J., Liberal Leviathan: the Origins, Crisis and Transformations of the American World Order, Princeton, Princeton University Press, 2011.

32 IKenBerry, G. J., «Introduction», en IKenBerRy, G. J., op. cit., nota 6, pp. 1-16, p. 1.

33 ACHARYA, A., op. cit., nota 17, p. 2.

34 Reus-Smit, C., op. cit., nota 4, pp. 566-570, p. 566.

35 WiEner, A., "Contested Meanings of Norms: A Research Framework», Comparative European Politics, vol. 1, 2007, núm. 5, pp. 1-17, pp. 7-10.

36 Reus-Smit, C., op. cit., nota 4, p. 557.

37 Ibid., p. 558.

38 Los actores en su relación con el orden pueden ser: promotores (aceptan el orden y muestran un elevado nivel de actividad), afianzadores (aceptan el orden y muestran un bajo nivel de actividad), subversivos (rechazan el orden y muestran un elevado nivel de actividad) y erosionadores (rechazan el orden y muestran un bajo nivel de actividad). En base al nivel de actividad y al carácter, asertivo o de contestación, las categorías básicas se pueden subdividir en: líderes, promotores, afianzadores ac- 
Es más, las propuestas más radicales —aquellas que de convertirse en acuerdos vinculantes y traducirse en políticas públicas afectarían a los elementos de las estructuras constitucionales- no provienen de los países emergentes asiáticos, sino de las potencias occidentales. Muchas de estas han asumido discursivamente las normas de inspiración cosmopolita impulsadas y generadas por organizaciones internacionales y actores de la sociedad civil global. Estas normas conformarían un nuevo orden (Worldfalia) que desafiaría algunos principios y normas de Westfalia. Paradójicamente, los países asiáticos, a menudo acusados de subversivos o incluso de antagonistas (líderes subversivos) ${ }^{39}$, frente a ellas se convierten en Estados pro statu quo. Devienen afianzadores activos de las normas westfalianas dejando atrás su tradicional papel de afianzadores pasivos. Sería el caso, como veremos, de su posicionamiento frente a normas de carácter cosmopolita como la RdP, que podría ser interpretada como un desafío práctico, que no de jure, al principio westfaliano de soberanía. La posición de resistencia de las potencias emergentes no es meramente pasiva. Desde sus nuevas posiciones de poder formulan contrapropuestas.

El orden internacional es más estable de lo que aparentan los llamativos cambios en la estructura de poder interestatal porque las instituciones que se han formado a partir de la conjunción de ideas y capacidades materiales de los actores hegemónicos socializan al resto y ayudan a consolidarlo ${ }^{40}, \mathrm{y}$ porque conjuga elementos de equilibrio, dominio y consentimiento ${ }^{41}$. En la actualidad, un Estado podría acumular más poder que cualquier otro Estado o actor sin que ello le brindara la oportunidad para crear unilateralmente un nuevo orden ${ }^{42}$. La globalización de los procesos y dinámicas internacionales, la complejidad de la interdependencia y la difusión del poder son frenos a las tentaciones hegemónicas unilateralistas.

tivos y pasivos, erosionadores activos y pasivos, subversivos y líderes subversivos. PAREJA AlCARAZ, P., Actores y orden en las Relaciones Internacionales. El papel de la República Popular China y Japón en la construcción del orden regional de Asia oriental. Tesis doctoral, Barcelona, UPF, 2011, pp. 56-68. Otras tipologías reducen los roles a: constructivos o cooperativos vs. destructivos o disruptivos, statu quo vs. revisionistas. Véase HARDIN, H., "China and the International Order», Remarks to the Open Forum, US Department of the State, abril, 2012. Disponible en: https://2001-2009.state.gov/s/p/of/proc/ $\mathrm{tr} / 11589 . \mathrm{htm}$.

39 Godemet, F., Expanded ambitions, shrinking achievements. How China sees the global order, Policy Brief, European Council on Foreign Relations, marzo, 2017, pp. 1-16. Disponible en: http://www. ecfr.eu/page/-/ECFR204_-_EXPANDED_AMBITIONS_SHRINKING_ACHIEVEMENTS_-_HOW_CHINA_ SEES_THE_GLOBAL_ORDER.pdf; SCHWELLER, R. L. y XIAOYU, P., «After Unipolarity: China's Visions of International Order in an Era of U.S. Decline», International Security, vol. 36, 2011, núm. 1, pp. 41-72; Sun, Y., "BRICS and China's Aspiration for the New "International Order" », UP Front, marzo de 2013, disponible en: https://www.brookings.edu/blog/up-front/2013/03/25/brics-and-chinas-aspiration-for-thenew-international-order/; ZHU, J., "Is China a challenge to the existing global order?», Open Global Rigths, agosto de 2013, disponible en: https://www.opendemocracy.net/openglobalrights/jiangnan-zhu/ is-china-challenge-to-existing-international-order.

40 IKENBERRY, G. J., "The logic of order: Westphalia, liberalism and the evolution of international order in the modern era", en IKENBERRY, G. J. (ed.), op. cit., nota 6, pp. 83-106, p. 89.

41 Cox, R. y Sinclair, T. J., Approaches to World Order, Cambridge, Cambridge University Press, 1996.

42 IKENBERRY, G. J., op. cit., nota 6, p. 99. 


\subsection{La evolución cosmopolita del orden liberal}

Desde la década de los noventa asistimos al resurgimiento de propuestas cosmopolitas para la gobernanza de la sociedad internacional. Estas provienen de los ámbitos académico y político, si bien en este último no son los Estados sus principales promotores. Los Estados se convierten en líderes normativos presionados por actores de la sociedad civil o por organizaciones internacionales gubernamentales. El giro cosmopolita lleva a planteamientos políticos que dejan atrás las limitaciones del imaginario nacional y asumen la existencia de intereses generales de la comunidad internacional, por encima de los Estados, que deben ser protegidos de manera conjunta por los actores y autoridades de la sociedad internacional. En este sentido el cosmopolitismo es un posicionamiento político-filosófico y una concepción de la gobernanza global ${ }^{43}$ que se construye socialmente alrededor de la idea de interés público global. A día de hoy, no es una realidad política consolidada, sino un conjunto de propuestas sobre la orientación que debe tomar la gobernanza global de la sociedad internacional.

De estas formulaciones surgen normas y proyectos de gobernanza cosmopolitas que pueden ser entendidos como parte de un proceso de larga duración de constitucionalización de la sociedad internacional y del Derecho internacional, que tendría como objetivo ordenarla y regularla a través de normas que limiten el poder de los Estados, reconozcan derechos y libertades a las personas, exijan responsabilidades por sus violaciones, y protejan los intereses generales de la sociedad internacional ${ }^{44}$. El proceso de concreción del cosmopolitismo en constitucionalización está sometido a continuos vaivenes en los que los avances retóricos son sucedidos por bruscos frenazos en la esfera políticopráctica ${ }^{45}$. Por ello defendemos que estamos ante un cosmopolitismo blando o suave que concilia la preservación del Estado y sus intereses con la paulatina articulación de mecanismos e instrumentos cosmopolitas de gobernanza.

Las potencias emergentes asiáticas se significan con determinación ante esta remodelación del orden internacional gracias a su nuevo posicionamiento en la estructura de poder interestatal ${ }^{46}$.

\section{LAS POTENCIAS ASIÁTICAS EMERGENTES FRENTE AL ORDEN INTERNACIONAL: DE RECEPTORAS A CREADORAS DE NORMAS}

Un orden se considera estable cuando sus estructuras constitucionales y normas fundamentales son respetadas por la mayoría de actores, incluyendo

\footnotetext{
43 Delanty, G., «The cosmopolitan imagination: critical cosmopolitanism and social theory», British Journal of Sociology, vol. 57, 2006, núm. 1, pp. 25-47.

44 Dunoff, J. L. y Trachtman, J. P. (eds.), Ruling the World? Constitutionalism, International Law and Global Governance, Cambridge, Cambridge University Press, 2009.

45 García Segura, C., op. cit., nota 5, p. 15.

46 AcharYa, A., op. cit., nota 17, p. 10.
} 
los más poderosos, durante la mayor parte del tiempo. La estabilidad viene favorecida por la legitimidad de la autoridad y la adaptabilidad de normas e instituciones a cambios y contestaciones. Por consolidado que esté un orden siempre hay tensiones normativas fruto de la diversidad de la sociedad internacional y del desajuste inevitable entre la generalidad de las normas y las situaciones específicas que generan disputas y argumentaciones que remodelan normas y conductas ${ }^{47}$. La interrelación entre poder y orden es evidente pero no es una simple correlación lineal, sino una compleja confluencia de múltiples factores materiales e ideacionales. El cambio normativo es más fácil y probable cuando una norma recibe el apoyo de múltiples potencias, es compatible con normas existentes ampliamente aceptadas y puede recurrir a más precedentes $-\mathrm{O}$ a normas más recientes- que sus oponentes ${ }^{48}$.

Los estudios empíricos existentes sobre el posicionamiento de algunas potencias asiáticas ante diferentes normas del orden internacional permiten, si no generalizar, sí señalar ciertas tendencias sobre los roles que desempeñan en los procesos de cambio y de contestación normativa en curso. A fin de analizar las tendencias generales, nos referiremos brevemente al proceso de construcción normativa del orden internacional.

\subsection{La dinámica de las normas y los roles normativos en el orden internacional}

El interés por las normas, como estándares de conducta apropiada vinculados a una identidad y consideradas instrumentos de la política mundial ${ }^{49}$, se introdujo en la disciplina de las Relaciones Internacionales de la mano del "giro constructivista» ${ }^{50}$. En los años noventa, la "primera ola» de estudios sobre la dinámica de las normas ${ }^{51}$ se orientó a demostrar la importancia de las normas en las relaciones internacionales, frente al predominio de la lógica del poder. Por razones pragmáticas, se apoyaban en una concepción muy estática de las mismas ${ }^{52}$. Matthew Hoffman lo justifica señalando que «congelaban» las normas: "Con el fin de facilitar el análisis y diálogo con otras perspectivas, las analizaban como estas lo habían hecho, como entidades re-

47 SANDholtz, W., «Dynamics of international norm change: Rules against wartime plunder», European Journal of International Relations, vol. 14, 2008, núm. 1, pp. 101-131, pp. 103 y ss.

48 Ibid., p. 109.

49 Finnemore, M. y SiKKINK, K., op. cit., 1998, nota 2, p. 891.

50 Checkel, J. T., «The constructivist turn in International Relations theory», World Politics, vol. 50, 1998, núm. 2, pp. 324-348.

51 Cortell, A. P. y Davis, J. W., «Understanding the Domestic Impact of International Norms. A Research Agenda», International Studies Review, vol. 2, 2000, núm. 1, pp. 65-87, p. 66; HoffMAN, M., «Norms and Social Constructivism in International Relations», en DENEMARK, R. A. y MARLIN-BENNETT, E. (eds.), The International Studies Encyclopedia, Nueva York, Wiley-Blackwell, 2017 (versión en línea), pp. 1-19, p. 3.

52 Wunderlich, C., «Theoretical Approaches in Norms Dynamics», en Müller, H. y Wunderlich, C. (eds.), Norms Dynamics in Multilateral Arms Control: Interests, Conflicts and Justice, Athens, Georgia University Press, 2013, pp. 20-47, p. 20. 
lativamente estáticas, con significados y restricciones específicos» ${ }^{53}$. Aunque algunos estudios integraron el cambio, lo hicieron de una forma colateral y limitada. Sería el caso del trabajo de Martha Finnerore y Kathryn Sikkink que, a pesar de ciertas críticas, sigue siendo un referente en el estudio del ciclo normativo. Según estas autoras el ciclo de una norma se compone de tres estadios: la emergencia de la norma, su expansión (norm cascade) y su internalización ${ }^{54}$. Reconociendo la utilidad de estos primeros trabajos, compartimos las críticas que se les imputan: el tratamiento de las normas como variables independientes, relativamente estáticas ${ }^{55}$; la no consideración de la contestación al marco normativo liberal (que asume que hay unos creadores de normas y otros receptores de normas fijos que a través de la socialización se integran en la comunidad de Estados occidentales); el sesgo liberal que refleja el estudio exclusivo de la difusión de normas liberales y cosmopolitas que se presuponen universales y deja traslucir un prejuicio de fondo, según el cual existe un grupo reducido de países ilustrados y de actores transnacionales - creadores de normas liberales - y un resto no ilustrado — seguidores de normas-; y, finalmente, la asunción implícita de linealidad del progreso que trasluce la presentación de los casos fracasados de resistencia al cambio normativo ${ }^{56}$. Es decir, son estudios que, preocupados por la conversión de los receptores tradicionales más que por la contestación, implícitamente presentan la resistencia a las normas cosmopolitas como ilegítima o inmoral ${ }^{57}$.

Este trabajo es deudor de las aportaciones más recientes de los autores de la «segunda ola» de trabajos sobre las normas que apuntan a cuestiones específicas en torno a qué normas importan ${ }^{58}$, y cómo, cuándo y por qué las normas cambian y hasta qué punto lo hacen ${ }^{59}$. En primer lugar, consideramos que la etapa de emergencia de una nueva norma puede incluir la transformación de una anterior y no únicamente la creación de una norma ex novo. En segundo lugar, en la línea de los trabajos de Wayne Sandholtz sobre el cambio normativo y de Antje Wiener sobre la contestación ${ }^{60}$, entendemos los sistemas normativos como sistemas dinámicos en los que las normas evolucionan

53 Hoffman, M., op. cit., nota 51, p. 3.

54 Finnemore, M. y SiKkinK, K., op. cit., nota 2, pp. 895 y ss.

55 Una concepción más dinámica define el proceso normativo como aquel por el que las normas y los regímenes se forman, se difunden, se internalizan y, una vez establecidos, se transforman reforzándose, debilitándose o erosionándose. WunderLich, C., op. cit., nota 52, p. 24.

56 Bloomfield, A., "Norm antipreneurs and theorising resistance to normative change», Review of International Studies, vol. 42, 2016, núm. 2, pp. 310-333, pp. 313-314.

57 AcharYA, A., «How Ideas Spread: Whose Norms Matter? Norm Localization and Institutional Change in Asian Regionalism», International Organization, vol. 58, 2004, núm. 2, pp. 239-275, p. 242, y Rethinking Power, Institutions and Ideas in World Politics. Whose IR?, Nueva York, Routledge, 2014.

58 Acharya, A., Whose Ideas Matter? Agency and Power in Asian Regionalism, Ithaca, Cornell University Press, 2009.

59 Se consideran autores de la segunda ola, entre otros, Antje Wiener, Alan Bloomfield y Shirley Scott, Wayne Shandholtz y Amitav Acharya. CoRTELl. A. P. y DAVIS, J. W., op. cit., nota 51, pp. 65-68.

${ }_{60}$ La contestación - actividad social que implica objeción- es un elemento explicativo clave de la dinámica normativa. Engloba una gama de prácticas sociales que, discursivamente, expresan desacuerdo con las normas y que varían mucho en la modalidad que adoptan. WiEnER, A., A Theory of Contestation, Nueva York, Springer, 2014, véase especialmente el cap. 1, pp. 1-15; SANDHOLTZ, W., op. cit., nota 47. 
a través de la interacción con el contexto ${ }^{61}$ y pueden transformarse a lo largo del proceso de difusión ${ }^{62}$. En tercer lugar, hacemos nuestros los conceptos de anti-emprendedores normativos (norm antipreneurs), adoptado por Alan Boomfield, Shirley Scott y colaboradores, y de resistentes creativos, utilizado por Malcolm Campbell-Verduyn ${ }^{63}$, útiles para describir las actuaciones de las potencias asiáticas. El primero describe a aquellos actores que resisten al cambio y favorecen la continuidad de las normas existentes ${ }^{64}$ y el segundo a aquellos que, admitiendo parte del cambio propuesto por los emprendedores, contestan ciertos aspectos y proponen otras versiones del cambio a través de tácticas más "positivas» que las de los anti-emprendedores ${ }^{65}$. Finalmente, en cuarto lugar, consideramos que el proceso normativo no es unidireccional y que los países no occidentales pueden ser más que receptores que hacen suyas las normas del orden liberal ${ }^{66}$. Durante siglos las potencias occidentales han socializado a los Estados no occidentales, deviniendo la socialización un componente crítico del orden hegemónico. A través de ella los Estados no occidentales forjaban su identidad como miembros de la sociedad internacional, aprehendiendo normas, valores y estándares de corrección fijados por los Estados hegemónicos. Sin embargo, la socialización ya no sigue este patrón unidireccional. Es un proceso bidireccional en el que los Estados no occidentales son también agentes activos que influyen sobre el contenido y los resultados de los procesos normativos ${ }^{67}$. El concepto de localización utilizado por Amitav Acharya subraya esta dinámica a la vez que explica porqué unas normas consiguen arraigar mejor que otras. La localización es un proceso de transmisión de ideas - sinónimo de normas- en el que los Estados periféricos toman prestadas ideas/normas sobre la autoridad y la legitimidad y las adaptan a las tradiciones y prácticas propias. Las ideas/normas que mejor encajan con las tradiciones locales son las mejor recibidas ${ }^{68}$. La resistencia a las normas universales demuestra que existen normas regionales o locales profundamente arraigadas en los sistemas regionales y contradice la asunción liberal de que las normas universales son morales y legítimas y las regionales inmorales e ilegítimas.

61 WIEnER, A., op. cit., nota 35, p. 6.

62 Bloomfield, A. y Scott, S. W., «Norms antipreneurs in world politics», en Bloomfield, A. y Scott, S. W. (eds.), Norms Antipreneurs and the Politics of Resistance to Global Normative Change, Londres, Routledge, 2017, pp. 1-19.

${ }^{63}$ Campbell-Verduyn, M., "Additional categories of agency. "Creatives resisters" to normative change in post-crisis global financial governance», en BLOOMFIELD, A. y ScotT, S. V., op. cit., pp. 140-158.

${ }^{64}$ Bloomfield, A. y Scott, S., op. cit., nota 62. Alan Bloomfield distingue varios tipos de antiemprendedores según su posición respecto a los extremos del eje cambio-resistencia normativa: emprendedores puros, emprendedores competidores, resistentes creativos y anti-emprendedores puros. Bloomfield, A., "Norm antipreneurs and theorising resistance to normative change», Review of International Studies, vol. 42, 2016, núm. 2, pp. 310-333.

65 Campbell-Verduyn, M., op. cit., nota 63, p. 146.

66 XIAOYu, P., «Socialization as a Two-way Process: Emerging Powers and the Diffusion of International Norms», The Chinese Journal of International Norms, vol. 5, 2012, núm. 4, pp. 341-367, pp. 341 y 344-345.

67 Ibid., p. 348.

68 ACHARYA, A., op. cit., nota 57 (2004), p. 244. 
Para explicar el rol de las potencias asiáticas emergentes en la dinámica de las normas seguiremos las premisas teóricas de Amitav Acharya, en las que se basa el proceso de localización. A través de él los tradicionales receptores de normas se convierten en emprendedores y construyen $-\mathrm{O}$ reconstruyenactivamente las ideas ajenas mediante el discurso, el encuadre, la inserción y la selección cultural, de manera que sean congruentes con las creencias y prácticas locales ${ }^{69}$. Las premisas que lo informan son la importancia de la agencia local y la resistencia y contestación como formas legítimas y morales de contribuir al orden internacional (que constituyen de hecho la primera fase - pre-localización- del proceso de localización $)^{70}$. Las causas que generan la localización son de diversa índole: grandes crisis del sistema internacional, sean políticas (guerras) o económicas (depresiones); cambios en la distribución del poder; cambios internos (procesos de democratización); y observación de los efectos (considerados positivos) de las nuevas normas ${ }^{71}$.

\subsection{El rol de las potencias asiáticas emergentes en los procesos normativos del orden internacional}

En la medida en que las potencias asiáticas emergentes cambian la estructura de poder pueden retar al dominio occidental en el ámbito de las ideas y las normas ${ }^{72}$. William Burke-White advierte de que cuando se escribe sobre el impacto del cambio de poder mundial en el Derecho internacional, en general, se asume que el declive de Estados Unidos y el ascenso de los BRICS $^{73}$ tienen un efecto homogéneo y perjudicial ${ }^{74}$. Su trabajo demuestra que no es así. Las potencias emergentes no rechazan las normas del sistema sino que articulan diferentes preferencias dentro de él que pueden desafiar la visión europea y estadounidense, o la que se supone que es esta, a menudo a través de una reafirmación del papel del Estado. Buscan cambios, acomodaciones, dentro del sistema ${ }^{75}$. En general, aceptan los elementos centrales del orden pero rechazan las jerarquías que se dan en las instituciones del orden ${ }^{76}$

69 Ibid., p. 245.

70 El proceso de localización consta de cuatro fases: pre-localización (resistencia y contestación), iniciativa local (emprendeduría y contextualización), adaptación (inserción y descarte), amplificación y universalización. Ibid., p. 251.

${ }^{71}$ Ibid., pp. 246-247.

72 McLaUchlin, T., "Great power accommodation and the processes of international politics», en Paul, T. V. (ed.), Accommodating Rising Powers. Past, present, and Future, Cambridge, Cambridge University Press, 2016, pp. 293-313, p. 306; XIAOYU, P., op. cit., nota 66, p. 365.

${ }^{73}$ Las siglas fueron utilizadas por primera vez en 2001 por el economista británico, entonces analista de Goldman Sachs, Jim O’Neill, para referirse a Brasil, India, Rusia y China, países que destacaban por el crecimiento espectacular de su economía. Más tarde se incluiría a Sudáfrica. O’NeILl, J., Building Better Global Economic BRICs, Nueva York, Goldman Sachs, Global Economics Paper, núm. 66, 30 de noviembre de 2001.

${ }^{74}$ Burke-White, W. W., «Power Shifts in International Law: Structural Realignment and Substantive Pluralism», Harvard International Law Journal, vol. 56, 2015, núm. 1, pp. 1-79, p. 2.

75 Ibid., pp. 5 y 7.

76 Stuenkel, O., Post-Western World. How Emerging Powers Are Remaking Global Order, Cambridge, Polity Press, 2016. 
y cuando se oponen a normas puntuales suelen ser propuestas normativas post-wesfalianas, de carácter cosmopolita ${ }^{77}$.

El giro hacia una mayor asertividad normativa de las potencias emergentes se identifica con la actitud de China ante la crisis financiera de 2008, con el desafío de las potencias emergentes a Occidente en la Cumbre de Copenhague de 2009 y con su apuesta por convertir el Grupo de los 20 (G20) en el foro más importante de cooperación económica internacional. Cuando, afirmadas por su poder económico, se reivindican, dejan translucir una tendencia general caracterizada por la defensa de una concepción dura de la soberanía nacional, la resistencia a la delegación de autoridad a entidades supranacionales y un rechazo a la estructura liberal de gobernanza en diversos ámbitos (económico, financiero, medioambiental) ${ }^{78}$. Así, la nueva asertividad asiática puede resultar problemática para algunos regímenes — derechos humanos, medioambiente- pero no para el orden en su conjunto ${ }^{79}$. En realidad la oposición de las potencias emergentes a las normas de inspiración cosmopolita difiere más en la forma que en el fondo respecto a la posición de los Estados Unidos y de las potencias occidentales. Las nuevas normas cuyos actores emprendedores son, en muchas ocasiones, actores transnacionales no estatales, son lideradas discursivamente por los Estados occidentales que, a menudo, las invalidan con su práctica política ${ }^{80}$. Juegan a la vez un rol de emprendedores y de anti-emprendedores, mientras que las potencias emergentes de Asia adoptan una posición más coherente - discurso y práctica se aproximan- y abierta, asumiendo el rol de anti-emprendedores o de resistentes creativos. Se da una situación paradójica porque, desde su nueva posición de poder, frenan algunos impulsos transformadores con propuestas alternativas. Las potencias emergentes, especialmente China, están insatisfechas con el carácter hegemónico del orden pero no están preparadas para ofrecer una visión alternativa global y viable, ni dispuestas a asumir los costes que exigiría. Centradas en sus problemas internos y conscientes de los réditos que obtienen del orden actual, optan por la «estrategia del gandul» rehuyendo grandes responsabilidades internacionales. En general, siguen un patrón de integración, participando en los regímenes internacionales y estableciendo una relación acomodaticia con la comunidad internacional. En determinados ámbitos siguen siendo receptores y continúan internalizando las normas económicas liberales ${ }^{81}$. No amenazan las reglas fundamentales del juego aunque intentan incrementar su papel como creadores-modeladores de normas. No son actores subversivos del orden vigente. Su nueva posición de poder les permite ser afianzadores activos y promotores: dejan de aceptar pasivamente y defienden activamente, oponiéndose a contestaciones cosmopolitas, centradas en el in-

77 Terhalle, M., The Transition of Global Order. Legitimacy and Contestation, Basingstoke/Nueva York, Palgrave/Macmillan, 2015.

78 Terhalle, M., «Reciprocal Socialization: Rising Powers and the West», International Studies Perspectives, vol. 12, 2011, núm. 4, pp. 341-361, p. 341.

79 Burke-White, W. W., op. cit., nota 74, p. 8.

80 Véase García Segura, C., op. cit., nota 5.

81 XiAOYU, P., op. cit., nota 66, pp. 356 y 360-361, y AchaRYA, A., op. cit., nota 17, p. 5. 
dividuo. Lo que sí contestan es el dogma de que las normas occidentales son mejores que las demás e insisten en participar en la atribución de legitimidad a las normas e instituciones del orden internacional.

El sistema jurídico internacional, flexible y resiliente, experimenta modificaciones originadas por los cambios del poder: el primero es la migración de algunos procesos normativos hacia los subsistemas, a menudo a expensas de las alternativas globales; el segundo es el pluralismo manifestado en la existencia de diferentes interpretaciones de los principios, normas e instituciones; el tercero es el refuerzo de Westfalia impulsado por Eastfalia, es decir, la defensa de una visión más estato-céntrica y tradicional del Derecho internacional que reafirma la soberanía, basa la legitimidad en los procesos e instituciones que se sustentan en la igualdad soberana y resitúa al Estado en el centro del proceso de desarrollo económico. Supone un retroceso en la individualización del Derecho internacional ${ }^{82}$. La incorporación de las potencias asiáticas como potencias normativas tiene consecuencias negativas, no para el orden jurídico internacional como tal, sí para el avance de Worldfalia.

\section{EL IMPACTO DEL ASCENSO DE CHINA SOBRE INSTITUCIONES Y NORMAS DEL ORDEN INTERNACIONAL}

Los cambios en el orden son más lentos que los cambios en el poder. Por ello, a pesar de los avances de los últimos años, las potencias asiáticas siguen teniendo un papel menor en cuanto a participación en las instituciones y en la creación y transformación de las normas. La región todavía presenta las ratios más bajas de aceptación de la jurisdicción de la Corte Internacional de Justicia, de membrecía de la Corte Penal Internacional, de firmas del Pacto Internacional de Derechos Civiles y Políticos y de otros tratados relativos a los Derechos Humanos, de acceso a la Organización Mundial de Comercio y de participación en el Centro Internacional de Arreglo de Diferencias Relativas a Inversiones ${ }^{83}$. Simon Chesterman califica de paradójica la baja participación regional en las normas e instituciones del orden internacional dados los elevados dividendos, económicos y de seguridad, que los países asiáticos han obtenido del orden internacional contemporáneo ${ }^{84}$.

Aun cuando Asia sigue jugando un papel secundario en el orden internacional, su reubicación en el mapa del poder mundial genera preocupación en las potencias occidentales por el impacto que pueda tener en él. Más allá de

82 Burke-White, W. W., op. cit., nota 74, pp. 76 y ss.

83 Esta tendencia se está invirtiendo en el ámbito del Derecho internacional económico, en el que las potencias asiáticas (China, India y Japón) son grandes usuarias del régimen de solución de controversias de la Organización Mundial del Comercio. También son líderes en la firma de Tratados Bilaterales de Inversión: el 80 por 100 de los países asiáticos ha firmado al menos uno y China es el segundo país que más ha firmado. Chesterman, S., "Asia's Ambivalence about International Law and Institutions: Past, Present and Futures», European Journal of International Law, vol. 27, 2016, núm. 4, pp. 945-978, pp. 946-947 y 960.

${ }^{84}$ Ibid., p. 946. 
las voces políticas interesadamente alarmistas y pesimistas que lo interpretan negativamente y advierten contra él, existe un consenso académico bastante generalizado que las matiza e incluso contradice ${ }^{85}$. A grandes trazos, el consenso defiende que las potencias asiáticas emergentes no quieren subvertir el orden creando uno nuevo, sino mejorar su relación con el existente. Su nueva posición de poder les permite aspirar a una adaptación de las estructuras jurídicas e institucionales más favorable a sus intereses. Por tanto, persiguen redistribución del poder de decisión dentro del orden y reconocimiento y respeto por parte de quienes lo crearon ${ }^{86}$.

A continuación analizaremos el impacto del cambio de poder sobre el orden a través de la posición de China ante la institución del multilateralismo y ante la norma emergente de la RdP. Su selección, frente a otras potencias asiáticas, se justifica por su mayor capacidad económica y su posición privilegiada como miembro permanente del Consejo de Seguridad (CdS). Si bien su conducta no es extrapolable a la de todos y cada uno de sus vecinos, comparte con ellos algunas preferencias y comportamientos, indicativos de tendencias regionales.

\subsection{China y el multilateralismo}

El multilateralismo es una forma institucional ${ }^{87}$ del orden internacional que está transformándose, y no necesaria o exclusivamente debido a la emergencia de Asia. Si bien las transformaciones no tienen porqué implicar crisis, muchos analistas la plantean ${ }^{88}$. La identifican con algunas instituciones multilaterales concretas (Naciones Unidas, Banco Mundial, Fondo Monetario Internacional, etc.), tiene múltiples dimensiones (legitimidad, eficacia) y está provocada por factores y actores diversos. El impacto de la emergencia de Asia en el multilateralismo suele percibirse en términos de amenaza a la institución, pero lo cierto es que buena parte de los males que esta padece son de origen interno y anteriores al ascenso de Asia. Son sus creadores quienes la cuestionan con sus malas prácticas. Se presupone a los países asiáticos emergentes una actitud diferente de la occidental frente al multilateralismo, cuando no hay una única visión occidental. Como veremos, ni China ni Asia en general discuten la validez y vigencia de la institución y su actitud frente al multilateralismo es muy similar a la estadounidense. Am-

85 Una notable excepción al consenso: Mearsheimer, J., The Tragedy of Great Powers, Nueva York, Norton, 2001; “China's Unpeaceful Rise», Current History, núm. 105, abril de 2006, pp. 160-162.

${ }^{86}$ NeL, P., «Redistribution and recognition: what emerging regional powers want», Review of International Studies, vol. 36, 2010, núm. 4, pp. 951-974.

87 Ruggie, J. G., «Multilateralism: the anatomy of an institution», International Organization, vol. 46, 1992, núm. 3, pp. 561-598. A efectos de este trabajo, utilizaremos el término tanto para referirnos a la institución como a las organizaciones internacionales multilaterales en las que se concreta.

88 Véanse: Newman, E., A Crisis in Global Institutions? Multilateralism and International Security, Londres, Routledge, 2007; RüLAND, J. G., "The rise of “diminished multilateralism": East Asian and European shopping in global governance», Asia Europe Journal, vol. 9, 2012, núm. 2, pp. 255-270. 
bas se distinguen del discurso de la Unión Europea, que no del de algunos Estados miembros ${ }^{89}$.

Los estudios empíricos sobre la participación de China en organismos multilaterales permiten calificar su concepción del multilateralismo de flexible, instrumental y estratégica. No tiene un modelo único, sino que adopta diferentes conductas y niveles de compromiso según los ámbitos materiales y las condiciones geopolíticas y geoeconómicas del momento. China desarrolla una retórica de «multilateralista entusiasta» cuando se trata de contrarrestar el unilateralismo estadounidense o de modular el temor que provoca su ascenso $^{90}$ y la utiliza para mejorar su prestigio y estatus internacional anteponiendo las recompensas sociales a las materiales ${ }^{91}$.

A partir de los años noventa Asia ha apostado por el multilateralismo, dando lugar a un auge del regionalismo sin precedentes ${ }^{92}$. Han proliferado las organizaciones multilaterales regionales. China participa en ellas y las prefiere a las globales, cuando no las crea o impulsa. Esta preferencia no debe interpretarse como un freno al multilateralismo global, sino como resultado de una diversidad saludable ${ }^{93}$.

Desde su creación, en pleno contexto bipolar, la República Popular China fue un país reacio al multilateralismo por identificarlo con las organizaciones controladas por Estados Unidos. Las rechazaba por considerarlas instrumentos del imperialismo ${ }^{94}$ y también como reacción a la falta de reconocimiento por parte del bloque occidental. Su viraje hacia el multilateralismo empezó a finales de los años setenta, coincidiendo con el cambio de política exterior estadounidense hacia China y con la apertura económica promovida por Deng Xiaoping. A partir de su ingreso en Naciones Unidas desarrolló una política de compromiso básico con el multilateralismo, participando pasivamente, cumpliendo los estándares mínimos e intentando aprovechar la experiencia técnica de las organizaciones. Finalizada la guerra fría profundizó su compromiso, convirtiéndose en un miembro activo, elevando sus estándares de

\footnotetext{
89 Estados Unidos tiene una visión instrumental del multilateralismo: acuerdos transitorios entre un grupo de Estados destinados a conseguir objetivos comunes-coyunturales. Para la Unión Europea es un fin en sí mismo, la ruta a través de la cual se favorece y se amplía la cooperación. Las potencias europeas, individualmente, no siempre se alinean con esta posición. Krause, J., "Multilateralism: Behind European Views», The Washington Quarterly, vol. 27, 2004, núm. 2, pp. 43-59. En la práctica, unos y otros, con diferentes intensidades, se identifican con el multilateralismo suave y se comprometen con la institución la mayor parte del tiempo pero con la reserva permanente de actuar unilateralmente si es «necesario». WALlERSTEIN, I., "Soft Multilateralism», The Nation, 15 de abril de 2004, disponible en: https://www.thenation.com/article/soft-multilateralism/.

90 Dittmer, L., "China's new multilateralism», en Wu, G. y Lansdowe, H. (eds.), China Turns to Multilateralism. Foreign policy and regional security, Londres, Routledge, 2008, pp. 21-33.

91 XIaOyU, L., «Social Rewards and Socialization Effects: An Alternative Explanation for the Motivation Behind China's Participation in International Institutions», The Chinese Journal of International Politics, vol. 3, 2010, núm. 3, pp. 247-377, p. 372.

92 García Segura, C., «El regionalismo en Asia Oriental», en Spoor, M. y Golden, S. (eds.), Regionalismo y desarrollo en Asia. Procesos, modelos y tendencias, Barcelona, CIDOB, 2006, pp. 15-59.

93 ACHARYA, A., op. cit., nota 17, pp. 105 y 110.

94 WANG, H., "Multilateralism in Chinese Foreign Policy. The Limits of Socialization», Asian Survey, vol. 40, 2000, núm. 3, pp. 475-491, p. 478.
} 
cumplimiento e internalización de las normas internacionales ${ }^{95}$. China intensificó su relación con las organizaciones multilaterales económicas y la fue extendiendo a otros ámbitos ${ }^{96}$. Su rol ha cambiado: su "participación cautelosa» ha evolucionado hacia el liderazgo ${ }^{97}$.

Medida en términos cuantitativos, la participación de China, igual que la de todos los países de la región, en organismos multilaterales regionales o universales ha aumentado exponencialmente: se ha adherido a la mayoría de organizaciones internacionales económicas, y ha empezado a participar con un nivel de actividad y liderazgo relevante en las organizaciones regionales y en otros foros informales no regionales, como el G20 o las cumbres BRICS. El poder económico de China y su compromiso con el multilateralismo se ha reflejado asimismo en el aumento del presupuesto dedicado a Naciones Unidas y a las operaciones de mantenimiento de la paz, así como en el incremento de sus cuotas en las instituciones financieras. Igualmente, ha aumentado el número de cargos de responsabilidad ocupados en organizaciones internacionales ${ }^{98}$. Eastfalia no reniega del multilateralismo formal e institucional de Westfalia.

En términos cualitativos la visión del multilateralismo de Eastfalia sí es diferente a la de Westfalia, o a una parte de ella, pero no es revolucionariasubversiva sino pro statu quo. La diferencia entre enfoques del multilateralismo tiene que ver con la idiosincrasia regional, no con las transformaciones del poder. China y Asia defienden un multilateralismo suave, de acuerdo a las reglas implícitas de la llamada Asia-Pacific way ${ }^{99}$, lo cual necesariamente tiene incidencia en algunos regímenes internacionales, contestando su desarrollo ${ }^{100}$. La versión asiática del multilateralismo reivindica las relaciones entre actores iguales y evita la juridificación de normas y regímenes ${ }^{101}$. China intenta evitar o remodelar las normas de gobernanza global de contenido cosmopolita, el «nuevo multilateralismo» identificado con el «cosmopolitismo moral» ${ }^{102}$ impulsado por algunas organizaciones internacionales en diferentes ámbitos (intervención, cambio climático, finanzas).

95 Hachigian, N., Chen, W. y Beddor, C., China's New Engagement in the International System, In the ring, but punching below its weight, Washington D. C., Center for American Progress, 2009, pp. 10-12.

96 WU, G., «Multiples levels of multilateralism. The rising China in the turbulent world», en WU, G. y LANSDOWE, H., op. cit., nota 90, pp. 267-289.

${ }_{97}$ XIE, Z., "The Rise of China and Its Growing Role in International Organizations», ICCS Journal of Modern Chinese Studies, vol. 4, 2011, núm. 1, pp. 85-96, p. 85.

98 La aportación al presupuesto de Naciones Unidas ha pasado del 0,7 por 100 de finales del siglo xx al 3,189 en 2009; el de las operaciones de paz, de 3,14 por 100 en 2003 a 3,93 en 2010. En el FMI China es ya el tercer contribuyente, a tan solo un 1 por 100 por detrás del segundo (Japón). Ibid., p. 89; GILl, B. y Huan, C., "China's Expanding Role in Peacekeeping Operations», SIPRI Policy Paper, núm. 25, 2009.

99 Es la sucesora de la ASEAN way. ACHARYA, A., «Ideas, identity and institution-building, From de "ASEAN way" to the "Asia-Pacific way"?», The Pacific Review, vol. 10, 1997, núm. 3, pp. 319-346.

100 Chesterman, S., op. cit., nota 83, pp. 31 y 39.

101 Keukeleire, S. y HooljmaAiJers, B., «The BRICS and Other Emerging Power Alliances and Multilateral Organizations in the Asia-Pacific and the Global South: Challenges for the European Union and its View on Multilateralism», Journal of Common Market Studies, vol. 52, 2014, núm. 3, pp. 582599, p. 594.

102 Acharya, A. op. cit., nota 57 (2014), p. 141. 
La actuación de China en las organizaciones multilaterales es cada vez más proactiva y la mayoría de analistas la califican de eficaz. Los pequeños gestos simbólicos realizados en el momento oportuno, como no devaluar la moneda en plena crisis financiera, o la adopción de políticas que marcan una diferencia con las occidentales, como las ayudas e inversiones no condicionales en África, hacen que, de manera sutil pero creciente, las organizaciones y foros internacionales sean más favorables a las visiones chinas en temas en los que Estados Unidos y China están en desacuerdo ${ }^{103}$.

Su nuevo papel de líder adopta diferentes versiones: activo-asertivo, elusivo y moldeador ${ }^{104}$. En la primera versión actúa como una potencia pro statu quo activa, abandona su anterior perfil bajo y se significa políticamente aumentando su participación en las operaciones de paz, adhiriéndose al régimen de Derechos Humanos, usando más el veto en el CdS o alineándose con países condenados por las potencias occidentales (Myanmar, Zimbawe, Sudán) ${ }^{105}$. En la versión elusiva del liderazgo actúa como una potencia revisionista activa situándose al margen de los regímenes multilaterales orquestados y controlados por Occidente, desarrollando, entre otras, su política de no condicionalidad de la ayuda frente a las normas del Comité de Ayuda al Desarrollo/Organización para la Cooperación y el Desarrollo Económico o creando la Organización para la Cooperación de Shanghái. Cuando ejerce el liderazgo modelador puede jugar ambos roles: revisionista-activa o pro statu quo activa. El primero se concreta, por ejemplo, en su preferencia por foros no convencionales, como el G20 o las cumbres BRICS, o en la creación de instituciones paralelas a las existentes, como el Banco Asiático de Inversión en Infraestructuras, cuando estas no le son favorables. Aunque las autoridades chinas, conscientes de la necesidad del multilateralismo no confrontacional ${ }^{106}$, se han esforzado en presentarlo como una organización complementaria, no rival, de las instituciones financieras clásicas, resulta muy difícil no ver en él un instrumento de proyección de su influencia económica en Asia y una forma de escapar al control occidental. Al contrario que el G20 o las cumbres BRICS no es un modelo alternativo sino la reproducción del existente pero controlado por China.

En síntesis, el multilateralismo chino de las últimas décadas se caracteriza por: el compromiso profundo, la asertividad y la madurez, plasmados en una mayor efectividad e influencia creciente en las organizaciones internacionales; un rol activo y constructivo que, puntualmente, alterna con uno defensivo

103 Así, frente a Estados Unidos, ha conseguido neutralizar el G20 evitando cualquier referencia a la revalorización del yuan. Olson, S. y PRestowitz, C., The Evolving Role of China in International Institutions, Report, Washington DC, The Economic Strategy Institute, 2011, p. 82.

104 Wuthnow, J., LI, X. y QI, L., «Diverse Multilateralism: Four Strategies in China's Multilateral Diplomacy», Journal of Chinese Political Science, vol. 17, 2012, núm. 3, pp. 269-290.

105 Holland, C., «Chinese Attitudes to International Law: China, the Security Council, Sovereignty, and Intervention", NYU Journal of International Law and Politics Online Forum, julio de 2012.

106 WU, G. y LANSDOWE, H., "International multilateralism with Chinese characteristics. Attitude changes, policy imperatives and regional impacts», en Wu, G. y LANSDOWE, H., op. cit., nota 90, pp. 3-18. 
para bloquear ciertas iniciativas ${ }^{107}$; la ampliación de los ámbitos de participación a temas de la agenda global (medio ambiente, seguridad, energía) ${ }^{108}$; la implicación selectiva ${ }^{109}$; y por una gran capacidad de aprendizaje ${ }^{110}$.

China ha hecho del multilateralismo una dimensión más de su política exterior $^{111}$ que persigue ante todo la estabilidad ${ }^{112}$, representada por los fundamentos de Westfalia, y la proyección de su poder creciente. La utiliza, de manera transversal, para defender sus objetivos: imponer la política de una sola China ${ }^{113}$ y frenar a Estados Unidos en Asia.

Dicho esto, el impacto de China sobre el multilateralismo como forma institucional en transformación no es muy distinto al de otras potencias. A pesar de tener relaciones históricamente muy diferentes con las principales instituciones multilaterales, todas las usan estratégicamente y las observan o eluden, excepcionalmente, en función de sus intereses. Lo problemático no es el uso estratégico, inevitable, sino la incoherencia entre la exaltación discursiva y el menosprecio político de la institución. Cuanto más implicada y comprometida está una potencia en una institución y cuanto mayor es su poder en el sistema, mayor es el impacto de su defección.

Finalmente, la influencia de China sobre algunas instituciones multilaterales concretas, algunos de sus principios y de sus políticas puede ser significativo en dos sentidos. En primer lugar, puede alterar las relaciones de poder en el seno de las organizaciones o añadir nuevos elementos a la arquitectura del sistema multilateral. Como hemos visto, China es ahora un jugador activo. Su capacidad económica y sus políticas de no injerencia y no condicionalidad la hacen un líder atractivo para muchos países del Sur global. Pero el poder estructural de la superpotencia tradicional hace que resulte difícil alterar el mecanismo de toma de decisiones en las principales organizaciones internacionales, con lo cual es probable que, sin abandonarlas, China apueste por un liderazgo paralelo en las organizaciones regionales. En segundo lugar, otra vía de impacto sobre las organizaciones multilaterales es la expansión del modelo ASEAN (siglas en inglés de la Asociación de Naciones del Sudeste Asiático) a todas aquellas que impulsa, lo que significa eludir la institucionalización y la creación de normas vinculantes y, más importante, retroceder en los intentos de creación de normas y regímenes globales de carácter cosmopolita y en la gobernanza global de los bienes públicos globales. Eastfalia contesta a Wordlfalia.

107 Como algunas resoluciones estadounidenses en la Comisión de Derechos Humanos de Naciones Unidas. Wuthnow, J., LI, X. y QI, L., op. cit., nota 104, p. 281. Olson, C. y Prestowitz, C., op. cit., nota 103 , pp. 7-14 y 21-34.

108 XIE, Z., op. cit., nota 97, p. 89.

109 Wu, G. y Lansdowe, H., op. cit., nota 106, p. 6.

110 Ibid. Contestando a la opinión mayoritaria, Hongying Wang plantea que la participación activa de China en organizaciones multilaterales no conlleva necesariamente socialización e internalización normativa. WANG, H., op. cit., nota 94, p. 487.

111 Wu, G., op. cit., nota 96, p. 288.

112 Olson, C. y Prestowitz, C., op. cit., nota 103, p. 13.

113 Ibid. y Wu, G. y LansDowe, H., op. cit., nota 106, p. 11. 


\subsection{China y la Responsabilidad de Proteger}

La contribución china a la formulación de la $\mathrm{RdP}^{114}$ es un ejemplo de la nueva relación de las potencias asiáticas con el consenso normativo existente en la que estas contestan el liderazgo occidental abandonando su posición de receptoras y convirtiéndose en creadoras normativas ${ }^{115}$, así como del proceso de localización por el cual los actores regionales deconstruyen y reconstruyen las normas globales hasta hacerlas compatibles con sus creencias e identidades ${ }^{116}$.

La RdP es significativamente relevante para la política exterior china porque afecta a los pilares básicos de su política exterior: la soberanía y la no intervención. Por ello, China ha adoptado un papel activo en su formulación, reinterpretando o limitando las propuestas iniciales, especialmente las cuestiones referidas al tercer pilar, lo que puede ser interpretado, en positivo, como un esfuerzo por hacer suya la norma ${ }^{117}$. El concepto alternativo «semi-oficial» de la «Protección Responsable» $(\mathrm{PR})^{118}$ significa que reconoce la intervención militar no consensuada bajo el tercer pilar (responsabilidad de la comunidad internacional cuando el Estado no puede hacer frente a la RdP), bajo condiciones mucho más restringidas que las planteadas por Occidente ${ }^{119}$. Cierto que su interpretación desemboca en una versión light de la RdP que, interpretada en negativo, desvirtúa la idea inicial y mina la norma al reducir la acción del CdS a la resolución, caso por caso, tal como ya venía haciendo ${ }^{120}$. Sin espacio para recorrer la evolución de la RdP apuntamos que, desde su formulación inicial en 2001 hasta la actualidad la norma ha ido evolucionando desde el extremo más duro de la normativización hasta el más blando, culminando en la eliminación de cualquier criterio preciso y vinculante sobre la intervención militar humanitaria y enfatizando el com-

114 No existe unanimidad sobre la consideración que debe recibir la RdP: idea-fuerza, principio emergente, norma-guía, norma. Nosotros la consideramos una norma emergente de cosmopolitismo blando o suave. García Segura, C. y Pareja Alcaraz, P., «Naciones Unidas como potencia normativa: el papel de la organización en la construcción de la Responsabilidad de Proteger», en Pons RÀFOLS, X. (dir.), Las Naciones Unidas desde España, Barcelona, ANUE, 2015, pp. 361-382.

115 Kozyrev, V., "Harmonizing "Responsibility to protect": China's vision of a post-sovereign world», International Relations, vol. 30, 2016, núm. 3, pp. 328-345.

116 Prantl, J. y NaKano, R., "Global Norm Diffusion in East Asia: How China and Japan Implement the Responsibility to Protect», International Relations, vol. 25, 2011, núm. 2, pp. 204-223, p. 205. Los autores proponen el concepto de bucle de retroalimentación para referirse a la localización o a la socialización de doble vía.

117 Garwood-Gowers, A., "China's "Responsible Protection” concept: re-interpreting the Responsibility to Protect (R2P) and military intervention for humanitarian purposes", Asian Journal of International Law, vol. 6, 2016, núm. 3, pp. 89-118, p. 91.

118 Aunque no ha sido adoptado como política oficial, el concepto fue presentado por el vicepresidente del China Institute for International Studies, considerado el think tank «oficial» del Ministerio de Asuntos Exteriores chino: RuAn, Z., «Responsible Protection: Building a Safer World», China Daily News, 15 de marzo de 2012.

119 GarWOOD-Gowers, A., op. cit., nota 117, p. 92

120 Chesterman, S., "Leading from behind: The Responsibility to Protect, the Obama Doctrines and Human Intervention after Libya», Ethics and International Affairs, vol. 25, 2011, núm. 3, pp. 279285 , p. 280 . 
promiso con la prevención ${ }^{121}$. En este proceso China y otros países no occidentales $^{122}$, especialmente los BRICS ${ }^{123}$, han jugado un papel determinante como anti-emprendedores y resistentes creativos, defendiendo la soberanía y la no injerencia, localizando la norma cosmopolita pero permitiendo, en definitiva, su entrada en el orden normativo internacional. China, socializada, desea integrarse en la sociedad internacional y, poderosa, bloquea el contenido cosmopolita de la norma conforme a sus intereses. Las autoridades chinas jamás se han opuesto abiertamente a la RdP. Conscientes de la importancia de construir una imagen de potencia responsable, en todas sus declaraciones en Naciones Unidas han reconocido que la soberanía implica responsabilidades internas además de derechos externos ${ }^{124}$. Incluso cuando, ante crisis humanitarias concretas, ha rechazado apoyar resoluciones del CdS, ha justificado su acción en base al Derecho internacional y a motivos prácticos ${ }^{125}$. Sus esfuerzos normativos han ido dirigidos a evitar la asociación entre RdP y acción coercitiva ${ }^{126}$.

Pueden distinguirse tres fases en la relación de China con la RdP. En una primera fase de oposición (2001-2005), China resistió firmemente la formulación inicial de la $\mathrm{RdP}^{127}$, contestando la nueva norma cual anti-emprendedor, porque chocaba con su interpretación de la soberanía y la no injerencia y porque sugería que el uso de la fuerza en intervenciones humanitarias podía ser autorizado por la Asamblea General u organizaciones regionales si el CdS se hallaba bloqueado. Beijing temía que Occidente utilizara la RdP como pretexto para un intervencionismo con objetivos estratégicos. Su resistencia fue activa, participando en los debates hasta conseguir una formulación conservadora que reducía a cuatro los supuestos de la RdP, centralizaba las decisiones en el CdS y no establecía criterios de acción generales sino que imperaba el «caso a caso» ${ }^{128}$. En la segunda fase (2005 a 2011), Beijing abrazó cautelosamente la RdP, lo cual se tradujo en un discurso de apoyo y una práctica de freno. Defendió la primacía del primer y segundo pilares (prevención y responsabilidad del Estado y apoyo de la comunidad internacional para que el Estado pueda cumplir con sus responsabilidades) y minimizó el

121 Prantl, J. y NaKano, R., op. cit., nota 116, p. 209.

122 Veáse Bellamy, A. y Davies, S., "The Responsibility to Protect in the Asia-Pacífic Region», Security Dialogue, vol. 40, 2009, núm. 6, pp. 547-574.

123 Véase García Segura, C. y Pareja Alcaraz, P., «La inspiración cosmopolita de la Responsabilidad de Proteger: Construcción normativa y disensos», en García SEguRA, C., op. cit., nota 5, pp. 64116, pp. 93-108; RotTman, P., Kurtz, G. y BrockmeIER, S., «Major powers and the constested evolution of a responsibility to protect», Conflict, Security and Development, vol. 14, 2014, núm. 4, pp. 355-377; ZIEGLER, C., "Critical perspectives on the Responsibility to Protect: BRICS and beyond», International Relations, vol. 30, 2016, núm. 3, pp. 262-277.

124 TeItT, S., «The Responsibility to Protect and China's Peacekeeping Policy», International Peacekeeping, vol. 18, 2011, núm. 3, pp. 298-312, p. 304.

125 Ibid, p. 302.

126 CHen, Z., "China and the Responsibility to protect», Journal of Contemporary China, vol. 25, 2016, núm. 101, pp. 686-700, p. 688.

127 ICISS, The Responsibility to Protect, Ottawa, IDRC, 2001.

128 Párrs. 138 y 139 del Documento final de la Cumbre Mundial de 2005, disponible en: https:// documents-dds-ny.un.org/doc/UNDOC/GEN/N05/487/63/PDF/N0548763.pdf?OpenElement. 
potencial del tercer pilar. No apoyó las resoluciones del CdS en los casos específicos: se abstuvo en el de Darfur (2006), en que se mencionaba por primera vez la RdP y votó en contra en los de Myanmar (2007) y Zimbawe (2008), en que se proponían sanciones. Como afirma Sara Teitt, durante este periodo preservó los vestigios de su anterior postura de defensa acérrima de la no injerencia al tiempo que salvaba la imagen internacional, no mostrándose insensible a las atrocidades masivas ${ }^{129}$. La tercera etapa, identificada con las crisis de Libia y Siria (2011-2012), empezó con un aparente giro hacia una interpretación más flexible de la RdP y acabó con un retroceso hacia posiciones más rígidas. Tras las críticas recibidas por su posición en la crisis de Darfur, preocupada por su imagen internacional y con intereses exteriores que exigían mayor implicación internacional, China flexibilizó su actitud en el caso de Libia. Apoyó la resolución 1970 del CdS, que invocaba la RdP del gobierno libio, y se abstuvo en la 1973 que dio lugar a la primera intervención bajo los auspicios de la RdP. Su incómoda abstención ${ }^{130}$ se explica, más que por un cambio normativo, por la confluencia excepcional de un conjunto de circunstancias: la evidencia de los ataques del régimen libio a la población civil en Benghazi, la fragmentación del gobierno de Gadhafi y, sobre todo, el apoyo de las organizaciones regionales ${ }^{131}$. El posterior desenlace de la acción de la OTAN en Libia provocó el rechazo frontal de China que, de nuevo, endureció su posición vetando las siguientes resoluciones sobre Siria que proponían sanciones. Al contrario que Rusia, no tenía intereses estratégicos ni relaciones económicas que justificaran su apoyo al régimen sirio. Los medios de comunicación chinos se hicieron eco de las razones de fondo — su oposición a que la intervención humanitaria derivara en apoyo a un cambio de régimen- pero su argumentación formal se basó en los propósitos de la Carta de Naciones Unidas y en consideraciones pragmáticas (las sanciones no resolverían el problema) ${ }^{132}$.

Tras su «defección» en el caso sirio, China ha seguido contribuyendo a la modelación de la RdP a través de la propuesta de la PR. Como potencia responsable, no abandona su compromiso con la sociedad internacional sino que pretende mejorar la norma insistiendo en el sentido de la protección y poniendo límites a posibles malos usos. Brevemente, la versión china de la RdP insiste en seis aspectos: el objeto de la PR es la protección de las personas inocentes; el gobierno del Estado es el primer responsable legítimo de la protección de sus ciudadanos y solo el CdS puede, en su defecto, desempeñar esta función; los medios de protección militar deber ser estrictamente limitados y deben haberse agotado todos los medios políticos y diplomáticos; el objetivo de la protección debe ser definido (mitigar la catástrofe humanitaria), no pueden causarse mayores males ni usarse para derrocar un gobierno;

\footnotetext{
129 TeITT, S., op. cit., nota 124, p. 309.

130 A pesar del apoyo, las declaraciones de los representantes chinos en el CdS reflejan una gran incomodidad. GARWOOD-GowERS, A., op. cit., nota 117, p. 98.

131 Garwood-Gowers, A., "China and the "responsibility to Protect": The Implications of the Lybian Intervention», Asian Journal of International Law, vol. 2, 2012, núm. 2, pp. 375-393.

132 Ibid., p. 390.
} 
los protectores deben responsabilizarse de la post-intervención; y las Naciones Unidas deben establecer mecanismos de supervisión, evaluación y rendimiento de cuentas que garanticen el buen funcionamiento de la $\mathrm{PR}^{133}$. De momento, no se ha concretado cómo se operacionalizaría la PR. Pero, más allá de su eficacia, esta propuesta normativa es significativa del poder de China, de su socialización ${ }^{134}$ y de su determinación a ser una potencia responsable. Easfalia defiende la esencia de Westfalia pero participa en la construcción de Worldfalia.

\section{CONCLUSIÓN}

En un mundo altamente interdependiente y globalizado el crecimiento económico posiciona mejor a las potencias asiáticas en el tablero del poder mundial. El ascenso de Asia desplaza a Occidente. Las potencias son fruto del orden internacional y modelan el orden internacional, lo cual no significa que un orden internacional liderado por Asia (Eastfalia) vaya a sustituir al liderado por Occidente (Westfalia). El poder estructural permite a las potencias tradicionales resistir parcialmente el envite de las nuevas. Afianzadas por su nuevo poder económico las potencias asiáticas, especialmente China, pueden dejar atrás el que ha sido hasta ahora su rol de afianzadoras pasivas del orden internacional westfaliano. ¿Pero quieren realmente estas potencias abandonar Westaflia y liderar la creación de un nuevo orden -Eastfalia-? Ciertamente no. Han sido grandes beneficiarias del orden actual y pretenden adaptarlo a sus nuevos objetivos, obtener mayores cuotas de poder y mayor capacidad de decisión. Su poder les permite jugar un rol activo, ser actores promotores y no agentes de las decisiones de otros.

Las potencias asiáticas han sido socializadas por el orden westfaliano, pero la socialización ha devenido un proceso de doble vía en que los diferentes actores se socializan mutuamente. En el plano normativo, las potencias asiáticas emergentes han dejado de ser receptoras de normas - afianzadoras pasivas o promotoras activas - para convertirse en creadoras. Su reciente asertividad se traduce en diferentes roles, según los Estados, las instituciones o las normas en cuestión: pueden crearlas, modelarlas, contestarlas, pueden ser anti-emprendedoras o resistentes-creativas.

El orden internacional contemporáneo evoluciona, muy lentamente, hacia un orden global -Worldfalia - que, bajo la presión de actores y au-

133 Garwood-Gowers, A., op. cit., nota 117, pp. 100-111.

134 Un examen detallado de las declaraciones oficiales y medios de comunicación chinos demuestra que no hay una única posición sino un rico debate, aunque, en general, los principales actores tienen una actitud positiva frente a la RdP y se muestran más sensibles a los derechos humanos y las cuestiones humanitarias. TIEWA, L. y ZHANG, H., "Debates in China about the responsibility to protect as a developing norm: a general assessment», Conflict, Security \& Development, vol. 14, 2014, núm. 4, pp. 403-427; Kounalalis, M., "China's position on international intervention: A Media and journalism analysis of its case for "Sovereignty" versus "Responsibility to Protect" principles in Syria", Global Media and China, vol. 16, 2016, núm. 3, pp. 149-167. 
toridades transnacionales, incorpora normas de espíritu cosmopolita. Los Estados las asumen a la vez que las frenan, pero no las rechazan abiertamente. Esta tensión cosmopolitismo-comunitarismo afecta a todos los Estados, sean o no potencias, sean estas nuevas o tradicionales. Las potencias emergentes no rechazan las instituciones y normas del orden internacional westfaliano - las adaptan - ni las del proyecto worldfaliano - las intentan limitar-. El análisis de la relación de China con el multilateralismo demuestra que el Asia emergente es más proclive que nunca a la institución, concretada en organizaciones regionales que siguen el modelo ASEAN. En las instituciones universales tradicionales, buscan aumentar su poder y si no lo consiguen optan por crear instituciones paralelas. En ningún caso reniegan del multilateralismo, sino del funcionamiento de ciertas instituciones multilaterales.

La relación de China con la norma emergente de la $\mathrm{RdP}$ es representativa de su nueva relación con los procesos de construcción de normas globales en los que Occidente ya no retiene el monopolio. China ha resuelto la tensión Westfalia-Worldfalia eliminando el componente cosmopolita en la aplicación práctica del tercer pilar pero manteniendo discursivamente el espíritu solidarista de la norma en los dos primeros pilares.

Los cambios en la estructura del poder interestatal no hacen prever la sustitución de Westfalia por Eastfalia. Asia no está dispuesta a liderar un nuevo orden y su defensa de la versión westfaliana de la soberanía y la no intervención frenan el avance de Worldfalia, lo que refuerza a Westfalia.

\section{RESUMEN}

WESTFALIA, WORLDFALIA, EASTFALIA. EL IMPACTO DE LAS TRANSFORMACIONES DE LA ESTRUCTURA DE PODER INTERESTATAL EN EL ORDEN INTERNACIONAL

El ascenso económico de Asia ha transformado la estructura del poder interestatal, desplazando a las potencias tradicionales e impactando sobre normas e instituciones del orden internacional liberal liderado por Estados Unidos y consensuado por las potencias occidentales desde el fin de la Segunda Guerra Mundial. El orden de Westfalia se enfrenta, a la vez, al giro cosmopolita (el proyecto de Worldfalia) y al envite de Asia ( $i$ un proyecto de Eastfalia?). A través del análisis de la relación de China con el multilateralismo y con la Responsabilidad de Proteger el artículo defiende que las potencias asiáticas, desde sus nuevas posiciones de poder, influyen en el orden internacional, participando en los procesos de creación de normas globales y modelando las instituciones conforme a sus nuevos objetivos e intereses. Dejan de ser receptoras de normas para participar activamente del proceso jugando diferentes roles. Sus actuaciones no conducen a crear y liderar un nuevo orden eastfaliano. Al contrario, refuerzan los principios de Westfalia y aceptan el avance de normas worldfalianas a la par que las intentan limitar.

Palabras clave: poder, orden internacional, cosmopolitismo, multilateralismo, Responsabilidad de Proteger, Westfalia, Worldfalia, Eastfalia, potencias asiáticas emergentes, China. 


\section{ABSTRACT \\ WESTFALIA, WORLDFALIA, EASTFALIA. THE INTERNATIONAL ORDER EXPOSED TO THE TRANSFORMATIONS OF THE INTERSTATE POWER STRUCTURE}

Asia's economic rise has transformed the structure of interstate power, both partially ousting traditional powers and influencing norms and institutions of the liberal international Order envisaged by Western powers and led by the United States since World War II. The current Westphalian order has to face the challenge of Asia (Is there an Eastphalian project?) and the cosmopolitan turn (Worldphalian project). Through the analysis of China's relation with multilateralism and the "Responsibility to Protect», this article argues that the new power status of Asian powers allows them to influence the international order, participating in global normative processes and shaping institutions according to their goals and interests. They are no longer norm-takers but norm-makers. They actively participate in global normative processes playing different roles, but always active ones. Their actions do not create and lead a new emerging Eastphalian order. In contrast, they reinforce existing Westphalian principles and accept the progress of Worldphalian norms while seeking to limit them.

Keywords: power, international order, cosmopolitanism, multilateralism, Responsibility to Protect, Westphalia, Worldphalia, Eastphalia, Asian emerging powers, China. 